\title{
OS PECADOS DA MODERNIDADE EM PECADOS SAFADOS DE BETTI BROWN $^{1}$
}

\author{
Evanir Pavloski ${ }^{2}$
}

\begin{abstract}
RESUMO: O objetivo desse trabalho é apresentar uma análise dos traços da modernidade encontrados em Pecados safados (1995) de Betti Brown e discutir o modo pelo qual essas estruturas, sejam elas conservadoras ou liberais, afetam o desenvolvimento histórico, sexual e psicológico da protagonista. No decorrer do trabalho, pretendemos revelar os aspectos contraditórios que envolvem os conceitos de modernidade. É nossa intenção mostrar que algumas das estruturas tradicionais, que haviam sido supostamente desconstruídas na modernidade, foram, na verdade, reforçadas e reorganizadas. Essa evolução ambígua é responsável não apenas pela liberação de discursos mantidos fora do cânone histórico e literário, mas também pelo aperfeiçoamento de diferentes tipos de preconceito, que formaram muitos dos conflitos sociais figirados no romance e amplamente presenciados nos dias de hoje.
\end{abstract}

Palavras-chave: Modernidade, sexualidade, pecados, preconceito.

ABSTRACT: The aim of this work is to present an analysis of the modernity traces found in Pecados safados (1995) by Betti Brown and discuss the way these structures, either conservative or liberal, affect the protagonist's historical, sexual and psychological development. As we proceed, we are intended to reveal the conflicting aspects that involve the concepts of modernity. We mean to show that some traditional structures, which were supposed to have been destroyed in the modern era, were actually reinforced and reorganized. Such ambiguous evolution is responsible not only for the liberation of discourses kept away from the historical and literary canon, but also for the specialization of different kinds of prejudice, which created many of the social conflicts depicted in the novel and widely witnessed nowadays.

Keywords: Modernity, sexuality, sins, prejudice.

\section{Introdução}

Tendo às nossas costas a entrada recém transposta de um novo milênio, os ideais de liberdade e pluralidade assuem novas conotações e constroem novos horizontes de significação. Contudo, não obstante a instabilidade característica da modernidade, certos moldes ainda permanecem íntegros, de forma dissimulada ou não. E mesmo quando a dissolução se

\footnotetext{
$1 \mathrm{O}$ presente trabalho vincula-se ao projeto de pesquisa intitulado "Identidades sociais" e coordenado pela Prof ${ }^{\mathrm{a}} \mathrm{Dr}^{\mathrm{a}}$ Aparecida de Jesus Ferreira (UEPG).

2 Professor efetivo na Universidade Estadual de Ponta Grossa (UEPG). Doutorando em Estudos Literários na Universidade Federal do Paraná (UFPR). E-mail: evanir.pv@gmail.com
} 
revelou iminente, os próprios discursos dogmáticos se integraram ao fluxo de transformação e rearticularam apenas a maneira de transmitir e impor os seus princípios.

O romance Pecados safados, publicado em 1995, desenvolve, por meio de uma dicção caracteristicamente irônica, problematizações agudas sobre uma das questões mais controversas da modernidade: a sexualidade. Se, por um lado, movimentos organizados conquistaram no último século reconhecimento e legitimidade; por outro, o preconceito e a discriminação ainda podem ser percebidos em discursos, práticas e instituições geradoras de perfis identitários estigmatizados e, comumente, oprimidos, senão pela violência, ao menos pelo silêncio.

Contudo, antes de abordamos a dimensão temática da obra e os seus desdobramentos críticos para a análise do tempo presente, devemos lançar alguma luz sobre o percurso de inovações e contradições que define a modernidade para que, dessa maneira, possamos compreender de uma forma um pouco menos incompleta o longo caminho que nos trouxe até aqui.

Marshall Berman entende a modernidade como um "turbilhão" de perspectivas e perigos que envolvem os indivíduos num processo constante de reavaliação e, conseqüente, renovação de conceitos tidos até então como impassíveis de contestação e crítica. Afirma ele que "existe um tipo de experiência vital - experiência vital - experiência de tempo e espaço, de si mesmo e dos outros, das possibilidades e perigos da vida - que é compartilhada por homens e mulheres em todo mundo, hoje. Designarei esse conjunto de experiências como modernidade" (Berman, 1981, p. 15).

Essa reestruturação, a qual se estabelece, entre outros fatores, pela expansão das fronteiras da ciência e do autoconhecimento humano, articula uma nova realidade, na qual as tradicionais amarras do pensamento social e político supostamente se dissolvem, aspecto que delineia um novo horizonte de experiências possíveis. Entretanto, o autor não deixa de salientar o caráter ambíguo desse processo, uma vez que a desestabilização social, ao destituir o indivíduo de suas aparentes certezas, lança-o em um vórtice de transformações e efemeridades que pode, ao longo do tempo, produzir novas formas de alienação. 
Assim, Berman percebe as conseqüências dessa perene renovação para a autoconsciência dos indivíduos, os quais vêem diante do espelho a desintegração de seus próprios reflexos. As pessoas tornam-se tão mutáveis quanto os diversos contextos que agora as cercam.

A experiência ambiental da modernidade anula todas as fronteiras geográficas e raciais, de classe e nacionalidade, de religião e nacionalidade, de religião e ideologia: nesse sentido, pode-se dizer que a modernidade une a espécie humana. Porém, é uma unidade paradoxal, uma unidade de desunidade: ela nos despeja a todos num turbilhão de permanente desintegração e mudança, de luta e contradição, de ambigüidade e angústia. (Berman, 1981, p. 15)

Por sua vez, Zygmunt Bauman (2001) atribui a característica de "fluidez" a esse conjunto de redimensionamentos do pensamento humano sobre si mesmo e sobre o mundo ao seu redor. Bauman compara a era moderna com a instabilidade constante dos líquidos, os quais estariam sempre prontos para sofrerem alterações de forma e para ocuparem o espaço que lhes cabe apenas temporariamente. Essa inconstância que, segundo o autor, é determinada muito menos pelo fator espaço do que pelo fator tempo, serviria como perfeita metáfora para o que ele chama de "modernidade líquida". Para ele, a modernidade escapa à rigidez dos sólidos e desafia a sua própria integridade ao contestar os recipientes formais que tentam the atribuir forma fixa. E durante esse processo derrete os sólidos que resistem à sua expansão. Como ele mesmo afirma sobre o espírito moderno,

Se o "espírito" era "moderno", ele o era na medida em que estava determinado que a realidade deveria ser emancipada da "mão morta" de sua própria história - e isso só poderia ser feito derretendo os sólidos (isto é, por definição, dissolvendo o que quer que persistisse no tempo e fosse infenso à sua passagem ou imune a seu fluxo). Essa intenção clamava, por sua vez, pela "profanação do sagrado": pelo repúdio e destronamento do passado, e, antes e acima de tudo, da "tradição" - isto é, o sedimento ou resíduo do passado no presente; clamava pelo esmagamento da armadura protetora forjada de crenças e lealdades que permitiam que os sólidos resistissem à "liquefação". (Bauman, 2001, p. 9)

Contudo, o autor também reconhece que essa desarticulação (e consequente dissolução dos sólidos que até então sustentavam 
posicionamentos e teciam redes de compromissos) ao partir os grilhões que reduziam os movimentos dos indivíduos tentou construir uma nova ordem realmente consistente, permitindo um lapso de tempo no qual novas relações acabaram se fortalecendo, emergindo na fluidez da modernidade e tornando-se parte dela. O capitalismo, por exemplo, torna-se uma margem sólida cercando o fluxo constante da modernidade e unindo seus participantes pela nova tradição do consumo.

O derretimento dos sólidos levou à progressiva libertação da economia de seus tradicionais embaraços políticos, éticos e culturais. Sedimentou uma nova ordem, definida principalmente em termos econômicos. Essa nova ordem deveria ser mais "sólida" que as ordens que substituía, porque, diferentemente delas, era imune a desafios por qualquer ação que não fosse econômica. (Bauman, 2001, p. 10)

O autor salienta que a fragmentação das estruturas tradicionais transmite uma sensação de liberdade individual, a qual torna-se ambígua ao se refletir sobre o fato de que essas estruturas não poderiam ter sido derrubadas sem serem substituídas por outros parâmetros, aparentemente mais liberais, mas tão rígidos quanto os anteriores. O capitalismo não ocupou apenas um espaço vazio no fluxo da modernidade, mas funcionou como um agente catalisador na formação desse espaço. O indivíduo se vê diante de um conjunto maior de possibilidades individuais e sociais, mas o apelo para a inclusão nas categorias arbitrariamente definidas continua fazendo parte dele. "Na verdade, nenhum molde foi quebrado sem que fosse substituído por outro" (Bauman, 2001, p. 13).

Juntam-se à crítica de Bauman outras vozes que, de com dicções similares, contestam o aspecto libertador da modernidade. Para autores como Sergio Paulo Rouanet e Michel Foucault a modernidade é pouco mais do que a substituição de um sistema de significação por outro aparentemente mais maleável. Assim, as tradições não foram destituídas de seu poder, mas inseridos em um reformulado padrão discursivo.

Rouanet (2001) afirma que o mundo moderno, afastando-se dos ideais iluministas, aproxima os indivíduos de uma nova forma de barbárie alimentada pelo capitalismo e dominada por uma falso universalismo. Segundo ele, "a individualidade submerge cada vez mais no anonimato do conformismo e da 
sociedade de consumo: não se trata tanto de pensar os pensamentos que todos pensam, mas de comprar os videocassetes que todos compram, nos aviões charter em que todos voam para Miami” (Rouanet, 2001, p. 9).

Nesse contexto, as discussões sobre questões de gênero e sexualidade transitam por diferentes esferas do pensamento sociológico, alcançando certa projeção e reconhecimento, mas que na praxis cotidiana ainda esbarram nos interditos e nas arbitrariedades da tradição. Especificamente no que se refere ao gênero feminino, se a secular repressão intelectual e econômica foi minimamente atenuada no decorrer do século XX, a liberdade sexual se revela ainda muito cerceada pela autoridade de pontos de vista essencialmente reacionários.

Diante desse panorama, a literatura representa um espaço possível e esteticamente privilegiado para um debate crítico sobre os limites impostos socialmente à sexualidade feminina, possibilitando um aprofundamento dos pontos de vista que buscam compreender a realidade para além dos rótulos deterministas.

A obra de Betti Brown problematiza as ambigüidades e os desejos femininos em uma época de fragmentações, identificações e rearticulações dogmáticas. Por meio de seu romance, vislumbramos aspectos essenciais dessa nova subjetividade feminina que, ainda em conflito com moldes tradicionais, busca a sua própria reinvenção na contemporaneidade.

\section{PECADOS HISTÓRICOS: ENTRE O SILÊNCIO E O DISCURSO}

Tradicionalmente, o gênero feminino teve seu papel e sua importância como agente histórico relegados ao pano de fundo dos acontecimentos considerados dignos de registro. Indubitavelmente, essa subordinação a um discurso oficial foi estendida a grupos étnicos e raciais ao longo dos séculos com o mesmo grau de arbitrariedade. Contudo, mesmo quando as narrativas míticas nacionais assumem força no século XIX e as chamadas literaturas das minorias passam a ser reconhecidas menos de cem anos depois, a figura feminina ainda busca seu lugar e sua valorização nos discursos históricos, inclusive naqueles que se propõem a questionar os paradigmas tradicionais. 
A Revolução Francesa e a ascensão do positivismo foram eventos decisivos para o fortalecimento de uma visão cientificista da historiografia que, supostamente tendo como objeto de estudo os fatos empíricos, legitimava o seu próprio discurso por meio de ideais de imparcialidade e independência. Essa aparente mudança de paradigmas, no entanto, atribuía uma inegável aura dogmática aos registros históricos, uma vez que, segundo os próprios princípios da ciência, um determinado fenômeno admite uma única explicação correta. Dessa maneira, o conhecimento histórico se cristaliza a partir de pontos de vista unívocos e restritivos, mas que, em essência, permanecem influenciados por variantes culturais e idiossincráticas.

Complementarmente, a formação da chamada ciência histórica promoveu uma completa cisão com os textos literários que, até o final século $\mathrm{XVIII,} \mathrm{eram} \mathrm{interpretados} \mathrm{como} \mathrm{registros} \mathrm{pertinentes} \mathrm{de} \mathrm{acontecimentos,} \mathrm{modos}$ de comportamento e sensibilidades de uma determinada época. A literatura, espaço de criação no qual as mulheres puderam expor minimamente a sua voz, foi relegada à esfera da pura imaginação e do irrealismo histórico.

Contudo, na modernidade tardia a historiografia é lançada em um processo de rearticulação impulsionado pelo reconhecimento de outras vozes narrativas que, por meio da exposição de suas perspectivas e experiências, se propõem a analisar a realidade experimental. Com isso, o conhecimento histórico passa a ser problematizado em seu status de verdade absoluta e a ser confrontado por uma multiplicidade de interpretações e olhares particulares. Diante dessa ampliação de horizontes metodológicos e críticos, o conceito tradicionalmente sólido do que seria factual passa a ser visto como discursivo e parcial, sendo portanto, passível de diferentes interpretações. Como defende a teórica Linda Hutcheon "só existem verdades no plural, e jamais uma só Verdade; e raramente existe a falsidade per se, apenas as verdades alheias" (Hutcheon, 1988, p. 146).

Essa ruptura dogmática acaba por reaproximar as fronteiras entre historiografia e literatura. Fato e ficção tornam-se categorias discursivas igualmente vistas como possibilidades de análise e registro de eventos. Como enfatiza Robert Scholes (1968), "the Bible is fiction because it's a madeupstory. This does not mean that it necessarily lacks the truth. Nor does it mean 
that the Bible may not contain fact. The relation between fact and fiction is by no means as simple as one might think"3 (Scholes, 1968, p. 01). Para o autor, a ficção merece um lugar de relevo nos estudos da história, dado o potencial interesse analítico despertado por suas produções, as quais revelam abertamente uma dicção interpretativa e culturalmente inscrita. Nesse sentido, cabe ressaltar o comentário de Linda Hutcheon para quem "a própria história e a própria ficção são termos históricos e suas definições e suas inter-relações são determinadas historicamente e variam ao longo do tempo" (Hutcheon, 1988, p. 141).

Dessa forma, as criações ficcionais reivindicam o seu reconhecimento como elementos constitutivos e documentais da história. Consequentemente, as mulheres vêem suas possibilidades de participação e interpretação do processo histórico se expandir para além dos limites impostos à literatura como simples campo de criação estética. Suas narrativas e suas experiências se tornam parte do spectrum de possibilidades de referência, identificação e denúncia que emerge na modernidade tardia.

A obra de cunho autobiográfico Pecados safados representa um desses relatos, em que podem ser vislumbrados os semi-novos desafios do gênero feminino que, em um mundo globalizado e aparentemente liberal, ainda luta para conquistar sua voz, seu direito ao prazer e sua participação efetiva na sociedade.

A trajetória da protagonista Isabel serve como processo de reavaliação de momentos representativos da modernidade, problematizando as novas articulações sociais que foram se formando ao longo desse período evidenciando aspectos reacionários que ainda permanecem. Capitalismo, feminismo, homossexualismo, religião, política, preconceito racial e social convivem num contexto esvaziado de certezas absolutas e imerso em dúvidas, ambigüidades e instabilidade.

Não é nosso objetivo aqui discutir os méritos estéticos da obra em questão, mas salientar o seu caráter expositivo dos conflitos modernos e a influência dos mesmos na formação de perfis identitários. Desejamos discutir

\footnotetext{
${ }^{3}$ Tradução livre: "a Bíblia é ficção porque é uma história produzida. Isso não significa que ela necessariamente nada tem de verdade. Nem significa que a Bíblia não contém nada de factual. A relação entre fato e ficção é de maneira alguma tão simples quanto alguém poderia pensar".
} 
sua importância como registro histórico-cultural, articulado a partir de um olhar interpretativo tradicionalmente preterido. Betti Brown cria o seu espaço no discurso histórico por meio da ficção.

Entretanto, não podemos nos satisfazer com o atual alcance da produção histórico-literária e nem com uma inclusão que objetive simplesmente inserir as mulheres como simples coadjuvantes no processo de construção histórica. É necessário dar um passo além. Como afirma Maria zilda de Matos,

não se trata apenas de incorporar as mulheres no interior de uma grande narrativa pronta, quer mostrando que as mulheres atuaram tanto quanto os homens na história, quer destacando as diferenças de uma "cultura feminina", perdendo-se, assim, a multiplicidade do ser feminino, podendo cair numa mera perspectiva essencialista. (MATOS, 1998, p. 69)

Assim, o romance de Betti Brown pode ser visto como um exemplo de uma nova proposta de discurso, de atuação e de sensibilidade, ou seja, o mundo descrito e interpretado pelos olhos de uma protagonista mulher e homossexual que assume as mais diferentes identidades e sobrevive na mais constante fragmentação.

Nesse sentido, o objeto literário e histórico aqui analisado representa, desde a sua própria escritura, um ato de relativização crítica dos paradigmas que arbitrariamente distinguem e separam discursos e gêneros.

Nosso estudo se desenvolverá, portanto, a partir da conflituosa trajetória da protagonista-narradora em sua tentativa de afirmar a sua sexualidade e a sua identidade diante de insituições e modelos de pensamento ainda marcados pela opressão discriminatória.

\section{PECADOS INSTITUCIONAIS: ENTRE A RELIGIÃO E A FAMÍLIA}

Desde o inicio da narrativa, quando encontramos a protagonista com apenas sete anos de idade, Isabel já se divide entre duas instituições formais que influenciam diretamente a construção de sua identidade: a escola e a família. A primeira de base severamente católica e a outra irrestritamente patriarcal. 
A obra inicia descrevendo um procedimento rotineiro no colégio Sacre Coeur, um semi-internato feminino, onde Isabel estuda. Já nas primeiras páginas do romance, a força da tradição ético-católica pode ser percebida como suporte de uma concepção autoritária e repressora de educação. A união de um ensino caracteristicamente dogmático e de evidente condicionamento ideológico cristão já delineia os contornos de uma instituição que, semelhantemente ao universo experimental, se mostra contraditório em seus próprios princípios. $\mathrm{O}$ aprendizado é visto como libertador, mas o seu processo se dá através de meios repressivos e arcaicos. A fé é tida como alimento do espírito, mas sua concepção só se sustenta pelas ameaças ao corpo.

A narradora-personagem não se identifica nas primeiras três páginas da obra. Suas descrições são feitas de dentro da massa sem nomes organizada pelas freiras. As identidades das alunas são apagadas no ambiente intra-muros do colégio. Elas são formatadas como números sem rostos, sem opinião e sem individualidade. Meros componentes do silêncio.

Madre Santos entrava onipotente no imenso pátio do colégio Sacre Coeur e apertava sua mini-castanhola:

- Tek! Imediatamente quinhentas alunas vestidas com o mesmo uniforme faziam fila, por altura, cada uma com sua respectiva sala de aula.

- Tek!

As quinhentas alunas, já em fila, entravam nos intermináveis corredores do colégio e paravam frente à capela. (Brown, 1995, p. 11)

Esse modelo de instituição educacional disciplinadora é apontada por Michel Foucault (1996) como elemento constantemente presente ao longo da história, ainda que sofrendo reestruturações em suas práticas controladoras e normalizadoras. Afirma ele que,

É enquanto indivíduo que se entra na escola, é enquanto indivíduo que se entra no hospital, ou que se entra na prisão. A prisão, o hospital, a escola, a oficina não são formas de vigilância do próprio grupo. É a estrutura de vigilância que, chamando para si os indivíduos, tomando-os individualmente, integrando-os, vai constitui-los secundariamente enquanto grupo. (Foucault, 1996, p. 111) 
Percebemos então, que Isabel não está inserida em um espaço pedagógico moderno, mas em uma estrutura tradicional marcada por atualizações derivadas dla necessidade de adequação a um novo contexto. Se as punições físicas são deixadas de lado, apela-se para a intimidação do espírito. O perigo das chamas do inferno substitui a palmatória, formando um amálgama de duas instituições tão controversas como antigas: igreja e escola. Controle, vigilância, punição e massificação se misturam na concepção de um método doutrinário na transmissão de conhecimento. Em tal contexto, as identidades heterodoxas se retraem, mas apenas na superfície.

Quando Isabel fala pela primeira vez de si mesma, ela imediatamente se identifica pela diferença. Seu desprezo por bonecas e por brincadeiras que reproduziam trabalhos domésticos surgem como características que não só a singulariza, mas também podem ser entendidas como uma forma de antecipação das escolhas que farão parte de sua vida. Em meio à massificação dos indivíduos, ela salienta as particularidades que a definem como sujeito.

Entretanto, o poder controlador da instituição e o desejo pela aceitação do grupo fazem com que ela mantenha essas diferenças distantes de seus atos. A discrição torna-se então parte de seu uniforme.

A verdade é que o meu missal era diferente e eu me sentia um pouco diferente por isso. Uma espécie de importância. Mas, naturalmente, como todas as crianças, eu não queria ser óbvia na diferença. Então, escondida da minha mãe, comprei na lojinha do Colégio um missal com bordas vermelhas como o de todas as outras, para me sentir exatamente igual a elas. Eu me percebia diferente, mas dissimulava. (Brown, 1995, p. 14-15)

Tal dissimulação fará parte constante da narrativa de Isabel, já que a convergência do discurso disciplinador escolar e da doutrina moralizante do catolicismo acaba por criar na menina um sentimento contínuo de repressão e medo. $\mathrm{O}$ conceito de pecado perseguirá a criança, a adolescente e a mulher ultrapassando os limites da fé cristã e se materializando em cada gesto que pretenda escapar dos padrões de conduta considerados normais.

$E$, além de tudo, eu culposamente tinha consciência de que esse meu pânico era totalmente imoral, criminoso, injusto, prevaricador, inescrupuloso e pervertido. Eu já me sentia uma 
pecadora só por assim pensar e isso jamais poderia ser revelado. [...] Tudo era pecado. Ou tentação. Tínhamos que resistir a todos os desejos porque, se não, poderíamos ser lançados às trevas e castigadas com os eternos tormentos do Inferno. (Brown, 1995, p. 16,19)

Tudo é pecado diante da imagem de um Deus vingativo e cheio de ira que, desde a ldade Média, serviu de instrumento de normalização individual e, consequentemente, de estabilização social. A modernidade não conseguiu suplantar totalmente essa representação aterrorizante, que foi adotada fervorasamente por aqueles que buscavam um solo firme diante do estremecimento das estruturas que lhes serviam como referência. "As freiras nos aterrorizavam dizendo que Deus tudo ouvia, tudo sabia. Ele estava em toda a parte. Portanto tínhamos que temer a tudo. Ele vivia no alto escondido num retiro cheio de nuvens e podia tudo vigiar. Era um juiz irado e severo" (Brown, 1995, p. 18).

Sem dúvida, o radicalismo religioso institucionalizado representa um dos aspectos contraditórios da modernidade. Contudo, isso não quer dizer que a doutrina tenha se mantido totalmente íntegra e fiel aos pressupostos que lhe deram origem. Suas transformações mais recentes foram impulsionadas em grande medida por outra força que se consolida na era moderna: o capitalismo.

A inclusão progressiva das relações econômicas no catolicismo cria divergências evidentes com os princípios segundo os quais a religião foi estabelecida e regulamentada. Isso não significa que em algum momento, desde a sua concepção, a lgreja Católica esteve isenta de qualquer interesse relativo ao acúmulo de bens materiais. Contudo, as renovações trazidas pela modernidade fizeram com que a instituição, vendo suas bases dogmáticas sacudidas e contestadas, ampliasse também seus horizontes oferecendo, ao mesmo tempo, abrigo tradicional aos refugiados do pensamento moderno e opção de escolha para os que abraçaram esse novo conjunto de relações. A Igreja reafirma suas bases ideológicas e renova, quando necessário, seu posicionamento diante de seus fiéis, obedecendo as novas exigências de mercado.

Madre Santos nos avisava que qualquer aluna que se arrependesse, que se confessasse e que desse pequenas (ou 
grandes) contribuições financeiras para as causas eclesiásticas teria maiores chances de receber a remissão total dos pecados e ficar livre das punições do Purgatório. Qualquer contribuição financeira iria para os humildes cofres da lgreja Católica e nos ajudaria a compensar qualquer desvirtude. (Brown, 1995, p. 4041)

O caráter de assimilação e intervenção da economia nesse contexto religioso-educacional mostra-se tão eficiente, que acaba por inserir nos rituais mais básicos do catolicismo. Quando lsabel diz que "o mais difícil era não se perder na conta para não ficar devendo nada. À vezes sabia que tinha rezado mais que o necessário mas, assim, já ficava com crédito para a próxima vez" (Brown, 1995, p. 41), percebemos claramente a inclusão de uma lógica essencialmente capitalista no próprio ato da confissão. A religião se insere no racionalismo do capital e cada vez mais os fiéis tornam-se consumidores de uma fé que muitas vezes prega o desapego pelos bens materiais.

No saguão principal do colégio, ao lado do balcão de informações, havia uma lojinha. Lá eram vendidos missais (onde tinha comprado o meu com bordas vermelhas), santinhos, peças do uniforme, cibórios, cálices, vidrinhos com água benta, alfaias, crucifixos de vários tamanhos, patenas, imagens de santos e as preciosas relíquias. As relíquias eram quadradinhos de veludo hermeticamente fechados. Elas variavam de tamanho, cor e preço. O mistério estava dentro do veludo e não poderia jamais ser aberto [...] Todas as vezes que alguém olhasse para uma delas, perderia alguns anos de Purgatório. (Brown, 39, 40)

Porém, ao longo da narrativa a protagonista muda de colégio por duas vezes, sem abandonar uma base educacional fundamentalmente religiosa. Dessa alteração de espaços, a qual significará também uma expansão de perspectivas, podemos extrair dois pontos importantes para a discussão.

Primeiramente, percebemos ao longo do texto que o acesso a esse tipo de educação Isabel é diretamente proporcional ao poder aquisitivo de cada família. Essa mistura de parâmetros educacionais com princípios morais e religiosos representa um certificado de qualidade para os alunos cujos pais podem arcar com as despesas correspondentes. As noções religiosas tornamse garantia de uma boa educação e a tradição católica é vista como um refúgio da ética na sociedade. Dessa maneira, o Sacre Couer representa o máximo do elitismo social, de forma que, à medida que Isabel muda de colégio há uma 
suposta redução da qualidade institucional de acordo com o decréscimo no status da instituição.

Em segundo lugar, notamos que ao ser transferida de uma instituição para outra, a protagonista encontra ambientes cada vez mais abertos e liberais, ainda que atrelados à moral católica. Essa modernização de certos padrões de comportamento se acentua nos ambientes escolares posteriormente frequentados ocupados pela garota e influencia seu desenvolvimento.

No Sion a Missa só era obrigatória uma vez por semana. Fazíamos orações e jejuns para castigar a carne "débil e abjeta". Mas, mesmo com tudo isso, eu tinha a impressão que o Deus do Sion era mais misericordioso. [...] Foi então que aconteceu a revolução: as freiras, de uma hora para outra, sem qualquer aviso prévio, tiraram o hábito por completo e abandonaram seus pseudônimos de trabalho, adotando seus nomes originais. Ninguém era mais madre, freira ou irmã com nomes inventados, mas, Lúcia, Sandra, Cristina. Era uma abolição. (Brown, 1995, p. $50,51,52)$

É interessante notar que essa alteração de costumes atinge também no modelo dessas instituições e promove a adoção de novos métodos e novas práticas. Contudo, esse processo não se efetiva totalmente. O paradoxo entre abertura e resistência é bem representado quando lsabel sugere que os alunos passem a se sentar em pares para melhor aproveitamento e desenvolvimento individual.

Acho que deveríamos aproveitar esse período de modernização e reformas para fazer mudanças aqui dentro também. A professora escutava e não fazia quaisquer comentários. A moda na época era "criatividade". As freiras diziam estar abertas para todas as novas idéias. [...] As outras alunas continuaram sentadas da mesma maneira tradicional. (Brown, p. 60, 61)

Quando Isabel é matriculada no Colégio Sagrado Coração ficam ainda mais evidentes as ambiguidades presentes num contexto de escola católicamoderna. Tradição e modernidade se misturam ainda mais nesse colégio onde, ao mesmo tempo em que as freiras conservam o uso do hábito, "padres de outros colégios eram convidados para nos dar aulas de educação sexual, naturalmente educação heterossexual. [...] Não podíamos fazer perguntas" (Brown, 1995, p. 95). 
Simultaneamente ao percurso escolar da protagonista, é apresentada a estrutura familiar na qual a garota se desenvolve. Fica claro então que as contradições produzidas pela modernidade não se reduzem aos muros das escolas, mas se espalham por outras instituições igualmente vistas como sólidas e articuladoras da sociedade.

Poderíamos iniciar com o questionamento proposto por Zygmunt Bauman: "pergunte-se o que é realmente uma familia hoje em dia? O que significa?" (Bauman, 2001, p. 13).

Não obstante as questões afetivas e subjetivas que envolvem a envolvem, a família representa não só o primeiro grupo social no qual os se vêem incluídos, mas também o primeiro conjunto de identificações possíveis aos quais eles são expostos.

Em outra perspectiva, a família, assim como a religião, é idealizada como um espaço que, estando à parte do universo público, serve como refúgio e espaço reflexivo na busca de soluções para os dilemas modernos. Como afirma André LÁZARO, "o interior da casa, a fina conservação, o bom gosto, na decoração, as expressões de afeto, tudo foi transformado em prazeres privados da burguesia. A burguesia esperava da familia um ambiente de ordem e estabilidade, em oposição ao mundo instável que, para além da porta da casa, perdia a nitidez" (Lázaro, 1996, 157).

Para Isabel, a familia é um campo de conflito, em que a ética individual se choca com um sistema tradicional de patriarcado. Nese sentido, casa e escola se complementam na articulação de um universo relacional controlador e autoritário.

Os horários na casa dos meus pais eram extremamente rígidos. As refeições não podiam atrasar nem um minuto sequer. [...] Havia também um horário marcado para todas as atividades como tomar banho, brincar com os cachorros, ler, chegar em casa, tomar água. Todos obedeciam sem questionar. Tudo tinha uma ordem, uma disciplina. (Brown, 1995, p. 22)

Esse espaço familiar, assim como o da escola católica, é visivelmente marcada por incongruências práticas que relativizam conceitos Nesse contexto, a concepção idealizada de família se reduz a uma camada de verniz 
cuidadosamente aplicada sobre uma estrutura problemática e inconstante que ameaça constantemente ruir ao longo da obra.

Internamente ao ethos familiar do romance, no entanto, as aparência e a projeção de um espaço idílico são ferozmente defendidas pelos pais de Isabel. Em certo sentido, a estrutura familiar per se importa muito menos do que a imagem pública que ela veicula.

Sob a ascensão do pai na carreira militar, por exemplo, paira o fantasma das suas origens africanas, preconceito que é retransmitido social e secualmente pela proópria personagem. A vida pública assume contornos disformes entre quatro paredes e a moral paterna se dissolve na entrada da cozinha ou do quarto de empregadas.

O grande segredo familiar - que poderia aparecer inesperadamente a qualquer hora num desses jantares - era que o avô de meu pai, meu bisavô, era negro! Sim, havia entre nós uma gota de sangue negro. Mas em hipótese alguma isso poderia ser revelado. [...] A cor da pele é de acordo com a classe. Entenda, minha filha, que a classe embranquece as pessoas. [...] Vou te contar outro segredinho Isabel. O teu pai não tem nenhum preconceito de cor, não tenho nada contra uma negrinha, mas gorda eu detesto. Aliás, não tem nada melhor do que uma negrinha magrinha na cama, que nem a [empregada] Kika. (Brown, 1995, p. 29, 30, 46)

Em contrapartida, a mãe de Isabel reúne todas as qualidades que seriam esperadas do estereótipo de uma mulher tradicional. Superficial, fútil, sexualmente frustrada e provida de uma cegueira meticulosamente desenvolvida, ela desempenha seu papel de esposa envolta pela sombra do marido e descarrega o silêncio de seus problemas em bens de consumo e na busca de um modelo estético.

Para minha mãe mudar de roupas diariamente era um dever da mulher, uma tarefa de esposa. Ela me dizia que cabia à mulher se renovar. Sempre. O homem não precisava, só a mulher. Era obrigação da mulher ser linda todos os dias. [...] E ela, ou não sabia mesmo ou fingia nada perceber. O importante para minha mãe era manter o casamento visível. Minha mão vivia através de meu pai. [...] Minha filha, na vida tudo é uma questão de aparência. Lembre-se do meu conselho: o que vale é a moldura e não o quadro. (Brown, 1995, p. 21, 22, 75) 
Dessa maneira o consumismo substitui a construção de uma identidade feminina autônoma e independente no espaço famíliar. Isso faz com que aspectos modernos e posicionamentos retrógrados acabem por se misturar no seio das famílias. Como afirma Jurandir Freire Costa, "no presente, o comércio de imagens e sensações é a âncora identificatória dos indivíduos [...] As drogas legais ou ilegais, os cuidados corporais, as imagens televisivas deixaram de ser meios marginais na construção de identidades subjetivas" (Costa, 1998, p. 215). O capitalismo preenche as rachaduras da modernidade.

A partir de tudo isso, percebemos que Isabel caminha sobre os limites tortuosos de instituições formais, as quais, sendo afetadas pela ação da modernidade e pela expansão descontrolada do capitalismo, constituem campos de referenciais complexos e fragmentados.

Os pecados religiosos aliam-se ao pecados familiares que, desde a preconceito do pai até a submissão incondicional da mãe, afastam a protagonista das categorias clássicas de adequação social. Para ela, ser acorrentada pela religião torna-se tão humilhante quanto ser amarrada pelo casamento. São formas diferentes, mas complementares do mesmo silêncio. Isso faz com que a garota busque sua individualidade além das portas de sua casa e dos vitrais da igreja, sem deixar de carregar consigo as marcas e os exemplo ali absorvidos. Seu processo de construção individual alimenta-se basicamente de fragmentos, sejam eles considerado postivios ou negativos.

\section{PECADOS SEXUAIS: ENTRE A NORMALIDADE E O DESVIO}

Desde o início da narrativa notamos o constante esforço de lsabel para se situar entre dois pólos socialmente construídos: o comum e o diferente. Sua subjetividade transita entre o desejo de mergulhar na uniformidade forçada ao se redor e o impulso de se destacar em meio a multidão. Contudo, esse conflito não se prolonga indefinidamente e são formados dois momentos distintos no percurso que nos é apresentado na obra. Sua hesitação diante da diferença, constantemente reforçado pelas instituições, acaba sendo minado à medida 
que sua sexualidade aflora e sua frustração em relação aos modelos de normalidade que lhe são apresentados se consolida. Gera-se então um novo conflito: a luta pelo reconhecimento da diferença, a qual não será sustentada em todos os ambientes, mas que se tornará parte integrante de sua vida.

Inicialmente, o desejo de Isabel é passar despercebida pelos olhares de outros indivíduos, sejam eles colegas de escola ou divindades religiosas. A personagem participa ativamente do processo normalizador que a envolve, tanto na família quanto na escola. Sua relutância em brincar com bonecas, por exemplo, é prontamente detectada pela família como algo preocupante e deflagra uma tentativa aberta de reverter um quadro supostamente anormal.

Eu detestava brincar com boneca. Eu detestava brincar de casinha com todos aqueles afazeres domésticos, mas adorava brincar com revólveres, cordas e algemas [...] Uma vez escutei minha avó Alzira conversando com minha mãe. Ela dizia que porque eu era menina eu tinha que brincar com outras meninas e, que era muito esquisito eu brincar com algemas e cordas. Era natural que brincasse com bonecas. Ela falava em um tom autoritário, convicta que toda menina tinha que brincar com bonecas porque era um treinamento para o dia em que fossem mães de verdade [...] Três meses depois eles voltaram. Na bagagem uma boneca americana que falava! (Brown, 1995, p. 23-24)

Já no ambiente escolar, fica claro desde o ingresso formal de lsabel que as diferenças não são bem vistas e muito menos bem vindas. $O$ controle de um grupo se estabelece mais facilmente quando mecanismo de normalização são efetivamente utilizados. Uniformes iguais, pensamentos parecidos e sexualidade única fazem com que desvios morais ou comportamentais representem riscos inadmissíveis para a estabilidade do grupo. Nesse contexto, a sexualidade não é apenas reprimida, mas expurgada quando em conflito com os paradigmas estabelecidos pela sociedade e, no caso específico das instituições representadas na obra, pela religião.

A Rosane foi mandada embora do colégio! Foi expulsa porque estava no banheiro se beijando com outra menina!! Imagine só! Duas meninas se beijando na boca!!![...] Virgem Maria! Deve ser pecado mortal! [...] Todas as freiras, as superiores $e$ as inferiores, foram unânimes em nos proibir de mencionar 
novamente o assunto. - Quem falar no nome desta pecadora outra vez vai ser severamente punida por Deus. Lembrem-se da ira de Cristo - nos dizia uma Madre Santos desesperada. (Brown, 1995, p. 42, 43)

Inserida num ambiente revestido por esse tipo de senso de justiça, Isabel aprende rápido que se diferenciar publicamente não é aconselhável. Em certo sentido, ser igual é ser livre para alimentar a diferença e nutrir-se dela em um silêncio supostamente provisório. Citamos como exemplo a passagem na qual Isabel fala sobre a experiência de responder cadernos de inconfidências na escola:

\begin{abstract}
Nesta época, por uma questão de sobrevivência, eu já tinha evidentemente desenvolvido uma astúcia de clandestinidade e logo achei uma solução fantástica: simplesmente copiar as respostas mais freqüentes das anteriores. Eu começava a descobrir que, quando a gente é diferente, a gente deve procurar ao máximo se identificar pelo igual. Eu tinha que ser óbvia. ${ }^{4}$ (Brown, 1995, p. 67)
\end{abstract}

Obviamente, o sistema repressivo implantado nas escolas reflete os modelos prescritivos vigentes na sociedade como um todo. Naturaliza-se um padrão de sexualidade normativo e se reduz ao nível da anormalidade os comportamentos conflitantes com esse paradigma.

Jonathan Ned Katz (1996) afirma que a heterossexualidade é um conceito moderno e influenciado por variantes sociohistóricas. $O$ autor argumenta que o homoerotismo é um tipo de sexualidade comprovadamente mais antigo do que a heterosexualidade. Katz cita exemplos que exemplos vão desde a Grécia Antiga até as camadas burguesas do final do século XIX, enfatizando a forma pela qual a imposição da norma heterossexual foi se construindo através da necessidade de afirmação de determinadas classes dominantes no decorrer da modernidade.

Os modos de organizar os sexos e a sexualidade variaram muito. Essa variação contesta a nossa suposição comum de que

\footnotetext{
${ }^{4}$ Como é explicado na própria obra, responder cadernos de inconfidências era um costume bastante disseminado nas escolas. O caderno era formado por perguntas que deveriam ser respondidas individualmente por todas as meninas requisitadas a fazê-lo pela dona do caderno. Ninguém tinha acesso às respostas a não ser que fosse uma das escolhidas para participar. Normalmente as perguntas envolviam preferências artísticas e sexuais.
} 
uma heterossexualidade essencial e imutável assume formas históricas qualitativamente diferentes. Eu sugiro que a própria heterossexualidade significa uma forma histórica ligada ao tempo - um modo historicamente específico de organizar os sexos e seus prazeres. [...] A invenção da heterossexualidade nomeava publicamente, normalizava cientificamente e justificava eticamente a prática da classe média de prazer de sexo diferente. (Katz, 1996, p. 45-46, 61)

Poder e capital surgem novamente como forças organizadoras e modificadoras das relações sociais modernas. Cria-se um conceito pela necessidade de poucos, normatiza-o para a uniformidade do grupo e naturaliza-o para a estruturação de uma justificativa científica e histórica. A heterossexualidade é inventada e necessita de uma prática contrária e marginal para sua própria solidificação.

Contudo, o desejo existe e sua concretização, ainda que mantida na marginalidade, exige seu espaço. Isabel exige seu espaço. Sua sexualidade faz com que ela busque desde muito cedo comunidades referenciais nas quais seu desejo não seja visto como uma ofensa. Ela passa a se identificar por um grupo que, ao contrário dos anteriores nos quais ela se incluía, se articula e se define pela diferença.

\begin{abstract}
Joana e eu nos beijávamos inúmeras vezes por dia. Nós tínhamos pressa para viver. Ao mesmo tempo não víamos solução para o nosso amor e então nos beijávamos mais ainda, adiando decisões. Queríamos deixar registros fortes todos os dias, isso era o que importava. Entretanto, esse ocultamento começou aos poucos a fazer diferença: Marilene, Sívia, Joana e eu tínhamos um segredo importante que nos fazia nos sentir superiores porque não seguíamos as regras tradicionais. Quebrávamos as convenções estabelecidas de uma forma radical. (Brown, 1995, p. 64)
\end{abstract}

Entretanto, o desafio às convenções da personagem se revela como um processo marcado essencialmente pela rebeldia e pela substituição de uma norma por outra. A busca de Isabel por sua liberdade sexual culmina, em um primeiro momento, na afirmação de uma identidade modelar e, de certa forma também arbitrária. A necessidade aparente de vinculo e identificação com 
grupos regulados por regras específicas enfatiza a dificuldade de criação de uma autonomia psicológica e comportamental.

Nós éramos um time de dez meninas e usávamos a expressão "ser do time". Só quem "era do time" sabia. [...] Descobri então que existiam mulheres de todas as idades, caras, raças e profissões que também eram "do time". Elas não existiam só em livros. [...] Nenhuma das minhas novas amigas queria se casar ou ter filhos. Era uma liberdade ilimitada incompreensível para quem seguia as responsabilidades "sugeridas" pela lgreja. [...] Uma onda de feminismo aparecia no mundo. Eu não entendia direito, mas era totalmente favorável. Tinha vontade de ir aos Estados Unidos desfilar pelas ruas com todas aquelas mulheres. (Brown, 1995, p. 69, 88, 101, 105)

Porém, as identidades assumidas através dessa constante transição referencial não conseguem preencher as expectativas individuais de Isabel já que seu caráter coletivo envolve, uniformiza e isola seus membros. Inserindose nesses grupos, originados e definidos pela oposição, a protagonista encontra um processo de apagamento das individualidades semelhante aquele das instituições formais das quais ela tenta escapar. "[...] parecia que minha identidade era pela metade. Eu me sentia apenas cinqüenta por cento" (Brown, 1995, p. 64).

Tal aspecto nos leva a refletir sobre a fragmentação e o deslocamento das identidades na modernidade. Indubitavelmente, a modernidade tornou visível a hibridez dos perfis identitários e possibilitou a adoção de múltiplas identidades sócias, dentre as quais os indivíduos transitam ininterruptamente. Esses deslocamentos, entretanto, estão intimamente ligados à inclusão dos indivíduos em grupos determinados que legitimam práticas e comportamentos. Nesse processo, o sujeito pode ser diluído na significação do grupo e ter a sua individualidade sujeita a outra espécie de uniformização. Certamente, a determinação de comunidades referenciais e argumentativas específicas que fornecem perfis identitários particulares é um dos signos da modernidade e pode, de certa maneira, representar um mecanismo normalizador diferente. Como afirma Peter McLaren, "democracia, através da construção de identidades formais, vazias, dá a ilusão de identidade enquanto apaga a diferença" (McLaren, 1997, p. 42). 
Essa determinação de certos espaços identitários não é intransponível, sendo perfeitamente possível a construção de identidades contraditórias e mesmo opostas. Porém, a própria existência desses limites sociais gera tensões, radicalismos, preconceito e intolerância. Sobre as divisões criadas pela quebra de padrões tradicionais no início da modernidade Zygmunt Bauman salienta que "a tarefa dos indivíduos livres era usar sua nova liberdade para encontrar o nicho apropriado e ali se acomodar e adaptar: seguindo fielmente as regras e modos de conduta identificados como corretos e apropriados para aquele lugar" (Bauman, 2001, p. 13).

Poderíamos então, ao invés de nos referir a uma pluralização de identidades, nos remeter a uma multiplicação de comunidades referenciais que sustentam identidades passíveis de assimilação pelos indivíduos. Como nos mostra a protagonista Isabel em Pecados safados,

Descobri que, paralelamente, uma revolução dentro de mim também acontecia e reparei que já não e impressionava tanto com as brancas pré-freiras masculinizadas. Agora era totalmente seduzida pelas coloridas pré-hippies, quase subversivas. [...] Os grupos não-oficiais do colégio - que não tinham nada a ver com a classe onde estudávamos - se subdividiam assim: as fumantes, as não-fumantes, as esportistas, as que namoravam (já tinham beijado de língua), as que nunca tinham namorado, as que se maquiavam, as que usavam sutiã, as que já tinham menstruado. (Brown, 1995, p. 52, 53)

Com a descoberta de sua própria sexualidade Isabel passa a fazer parte de uma matriz referencial que ordena suas outras identidades. Ela passa a se reconhecer como lésbica e assume as conseqüências sociais dessa afirmação. Seu primeiro contato com a própria sexualidade e o termo que a definiria provoca na personagem estranhamento e insegurança.

Minhas mãos então gelaram, minha boca secou e eu comecei rapidamente a repetir "lésbica, lésbica, lésbica", para não esquecer. Então existia isso? A Rita era lésbica também? E a Rosane, que foi expulsa do Sacre Coeur? Será que eu era lésbica? Será que a Sívia, a Marilene e eu éramos as únicas lésbicas do mundo? [...] A palavra lésbica quase não era usada. De algum modo eu achava que usar a palavra lésbica era pior do 
que dizer do time. $O$ pecado parecia ser maior com a palavra lésbica. (Brown, 1995, p. 56, 69)

Após esse primeiro contato, visões valorativas e idealísticas em relação ao grupo como espaço privilegiado para a liberdade sexual passam a se inscrever no discurso de Isabel. Percebemos, dessa maneira, que a legitimação de um grupo se sustenta, muitas vezes, não apenas na diferença, mas também em um ideal de superioridade. Como salienta a protagonistanarradora do romance:

Afinal elas faziam sexo do mesmo modo que os pais, avós e bisavós delas. Aquela maneira aprovada, imposta. Em compensação, nós desobedecíamos ao mundo, recusávamos o prazer oficial. A heterossexualidade era séria, convencional. A homossexualidade não. Se quiséssemos, podíamos ter sexo com mulheres e com homens. Nossa perspectiva era, então, comprovadamente maior. (Brown, 1995, p. 97)

Esse tipo de valorização ideológica do grupo como superior à ordem convencional estabelecida é apontada por Jonathan Katz como intrínseca ao discurso das feministas lésbicas, o que representa uma forma de reação à marginalidade categórica ao qual elas são submetidas. Afirma o autor que:

O uso social dominante, dizem as escritoras, distingue uma lésbica de uma mulher. Isso quer dizer que uma mulher de verdade depende de um homem. A que não depende de um homem não é uma mulher de verdade. Inclui-se em outra categoria, a das lésbicas, é alguém diferente de uma mulher. As lésbicas radicais observam que a distinção entre lésbica e mulher revela a posição inferior das mulheres heterossexuais. [...] O poder da linguagem e da política de classificação é uma parte importante dessa crítica das feministas lésbicas do início dos anos 70. (Katz, 1996, p. 146)

A personagem lsabel também enfatiza essa distinção ao se referir constantemente ao exemplo da identidade fundamentalmente heterossexual e passiva assumida por sua mãe em seu universo relacional, o que encaminha a protagonista para uma rejeição do papel subalterno da mulher convencional. 
Elas freqüentavam os jantares para serem vistas e não ouvidas. As esposas se tornavam então inimigas naturais e se temiam mutuamente. Era uma verdadeira guerra pela disputa de elogios. [...] Minha mãe acreditava que moldar constantemente seu corpo era a única fonte de alegria. $O$ outro acesso seria continuar em seu papel de esposa de militar, ou melhor, esposa de coronel. (Brown, 1995, p. 107-108)

Em alguns momentos da narrativa, principalmente no início de seu desenvolvimento sexual, vemos tentativas da protagonista em se livrar dos grupos e categorias moldadas que lhe oferecem referências. "Não tinha nenhuma preferência e continua achando que podia beijar meninas e meninos porque eles me beijavam também" (Brown, 1995, p. 84). Esse esforço para construir sua individualidade é constantemente influenciado pelo condicionamento religioso e familiar que moldaram sua vida, o que forma uma síntese das diferentes concepções de pecado reconhecidas por essas instituições.

No fundo tinha certeza de quando fosse mais velha iria me apaixonar e me casar com um lindo homem de olhos azuis e ter muitos filhos. Essa atração por mulheres era apenas uma fase pela qual estava passando. Talvez eu ainda não estivesse pronta para rapazes. [...] Iríamos logo conhecer a verdadeira ira de Cristo e provavelmente não teríamos mais a prometida vida eterna. Deveríamos nos sentir culpadas agora e preocupadas com nossos destinos depois da morte. Passaríamos séculos no Purgatório. Nós não pertencíamos mais ao rebanho de Deus. (Brown, 1995, p. 69, 77)

Entretanto, esse tênue limite no qual caminha Isabel acaba por fundamentar sua visão do mundo que ao seu redor se mostra contraditório e discriminador. Os olhos de Deus acabam sendo substituídos pelos olhos da sociedade que tenta totalizar seus conceitos normativos e condenar como pecaminoso todo e qualquer ato que se projete para fora do grupo onde deve permanecer contido. "O importante era nos sentirmos adaptados. Lá dentro nosso prazer era autorizado. Nós podíamos se visíveis” (Brown, 1995, p. 123).

Ao procurarmos na pós-modernidade uma solução para esse paradoxo, devemos também nos questionar quantas obras como Pecados safados são lidas e analisadas critica e produtivamente. Devemos questionar também qual 
o real alcance das discussões levantadas por esses textos. Se a pósmodernidade representa um momento de reavaliação dos fragmentos e construtos dos últimos dois séculos, a sexualidade deve ocupar um representativo espaço de problematização social.

\section{CONSIDERAÇÕES FINAIS}

Ler a obra Pecados safados é obter um relato consciente dos níveis de contradição e conservadorismo presentes nas sociedades contemporâneas. Por meio da trajetória da protagonista-narradora, percebemos o nível de problematização que a dissolução de certas estruturas tradicionais, o fortalecimento de outras e a criação de novos conceitos moduladores e normalizadores produziram no contexto atual das relações humanas. Vários analistas da modernidade já indicavam o caráter contraditório desse momento histórico, que, em muitos casos, ostenta um liberalismo ideológico e econômico como fonte geradora de grupos excludentes e fechados.

Em certo sentido, a era moderna traz como signo de ruptura com a tradição a possibilidade do indivíduo, através da fragmentação de sua identidade, participar de grupos distintos em diferentes contextos relacionais. Contudo, a teorização valorizadora da diferença não produz uma troca produtiva de experiências, apenas atribui aos indivíduos certa autonomia na escolha das identidades que deseja assumir, que recorrentemente são limitadas pelos paradigmas éticos da comunidades referenciais que as representam.

Pecados safados representa uma voz ao mesmo tempo lançada na história e formada a partir dela. É um dos relatos que tentam alcançar um espaço discursivo tradicionalmente negado pela historiografia e pelo cânone literário ao longo dos séculos. A pós-modernidade, mesmo com suas ambigüidades problemáticas, é um novo horizonte de perspectivas em constante desenvolvimento, o que possibilita que a de Betti Brown sirva como um dos múltiplos caminhos reflexivos para a análise das contradições e arbitrariedades que caracterizam o mundo referencial nos dias atuais. 


\section{REFERÊNCIAS BIBLIOGRÁFICAS}

BAUMAN, Zygmunt. Modernidade líquida. Rio de Janeiro: Jorge Zahar Editor, 2001.

BERMAN, Marshall. Tudo que é sólido desmancha no ar. São Paulo: Companhia das Letras, 1981.

BROWN, Betti. Pecados Safados. Rio de Janeiro: Record, 1995.

COSTA, Jurandir Freire. Sem fraude, nem favor: estudos sobre o amor romântico. Rio de Janeiro: Rocco, 1998.

FOUCAULT, Michel. A verdade e as formas jurídicas. Rio de Janeiro: Nau, 1996.

HUTCHEON, Linda. Poética do pós-modernismo. Trad. Ricardo Cruz. Rio de Janeiro: Imago Editora, 1988.

KATZ, Jonathan. A invenção da heterossexualidade. Rio de Janeiro: Ediouro, 1996.

LÁZARO, André. Amor: do mito ao mercado. Rio de Janeiro: Vozes, 1996.

MATOS, Maria Izilda Santos de. Estudos de gênero: percurso e possibilidades na historiografia contemporânea In: Cadernos Pagu , no 11, 1998.

MCLAREN, Peter. Multiculturalismo crítico. Trad. Bebel Orofino Schaefer. São Paulo: Cortez, 1997.

ROUANET, Sergio Paulo. Mal-estar na modernidade - Ensaios. São Paulo: Companhia das Letras, 2001.

SCHOLES, Robert. Elements of fiction. New York: Oxford University Press, 1968. 